Proc. of the XI Int. Conf. - Ion Implantation and other Applications of Ions and Electrons, Kazimierz Dolny 2016

\title{
Ion Beam Formation of Electrocatalysts for Direct Methanol and Ethanol Fuel Cells on the Basis of Carbon Catalyst Supports
}

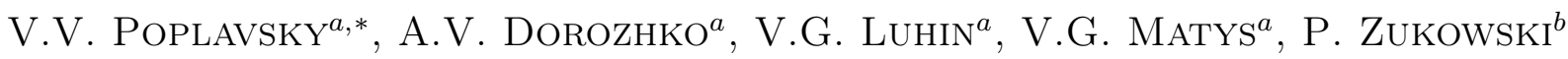 \\ AND K. CZARNACKA ${ }^{c}$ \\ ${ }^{a}$ Belarusian State Technological University, 13a, Sverdlov Str., 220006 Minsk, Belarus \\ ${ }^{b}$ Lublin University of Technology, Nadbystrzycka 38a, 20-618 Lublin, Poland \\ ${ }^{c}$ University of Life Sciences in Lublin, 20-612 Lublin, Poland
}

\begin{abstract}
Ion-beam modification of materials whose service properties are mainly controlled by the surface composition is of especial interest, in particular, for electrocatalysts, namely electrodes of fuel cells - perspective chemical current sources. A catalyst is needed for effective operation of fuel cell. In this paper active layers of the electrocatalysts were prepared by ion beam assisted deposition of catalytic (platinum) and activating (cerium) metals onto carbon (AVCarb ${ }^{\circledR}$ Carbon Fiber Paper P50 and Toray Carbon Fiber Paper TGP-H-060 T) catalyst supports. Formation of layers by ion beam assisted deposition by means of the deposition of metal and mixing of precipitating layer with the substrate by accelerated ions of the same metal, was carried out. Metal deposition and mixing between the precipitable layer and surface of the substrate by accelerated $(U=10 \mathrm{kV})$ ions of the same metal were conducted from a neutral vapor fraction and plasma of vacuum arc discharge of a pulsed electric arc ion source. Study of the morphology and composition of layers was carried out by the scanning electron microscopy, energy dispersive X-ray microanalysis, X-ray fluorescence analysis, and the Rutherford backscattering spectrometry methods. According to the investigations with the use of cyclic voltammetry, the electrocatalysts with the prepared layers exhibited catalytic activity in the reactions of electrochemical oxidation of methanol and ethanol, which form the basis for the principle of operation of low temperature direct methanol and direct ethanol fuel cells.
\end{abstract}

DOI: $10.12693 /$ APhysPolA.132.278

PACS/topics: 68.37.Hk, 81.15.Jj, 81.05.U-, 82.45.Jn, 82.80.Fk, 82.80.Yc, 88.20.ff, 88.30.pd, 88.30.pf

\section{Introduction}

Non-equilibrium surface alloying of materials by accelerated metal ions enables the introduction of a thin surface layer of controlled amounts of dopant at an atomic level. The most interesting can be the ion-beam modification of functional materials whose properties are mainly determined by the surface structure, in particular heterogeneous catalysts of chemical reactions [1-4]. First of all it seems appropriate to form by ion beam catalyst layers on the surface of electrocatalyst - a relatively small size electrode of alternative electrochemical energy devices.

One of the areas of alternative energy is the use of hydrogen as an energy source. Prospects for the development of hydrogen energy indicate hydrogen production, storage, and distribution as well as its use for electricity generation using fuel cells. Fuel cells generate electricity by oxidation-reduction reactions of reactants coming from the outside. Fuel and oxidant are supplied separately and continuously to the electrochemical cell and react at the two electrodes. In the fuel cell, the chemical energy of the fuel is converted directly into electricity. These power sources are characterized by high efficiency, low toxicity of the reaction products, as well as the ability to create a modular design to achieve high power. Hy-

*corresponding author; e-mail: vasily.poplav@tut.by drogen fuel cells are the most developed. Recently, there have been made intensive attempts to develop fuel cells for the direct oxidation of organic alcohols - ethanol and methanol (direct methanol fuel cell - DMFC, direct ethanol fuel cell - DEFC). However, the use of organic fuels allows removing hydrogen reception problem, cleaning, storage and distribution of hydrogen to simplify the fuel supply system. In a direct alcohol fuel cell system, methanol or ethanol is converted directly to hydrogen.

Electrochemical processes underlying the principle of operation of fuel cells occur only in the presence of a catalyst. Platinum is used as a basic catalytic metal for the electrocatalysts. To achieve a high activity catalyst the additional activating metals are introduced into the electrocatalyst layers. The high cost and scarcity of platinum group metals challenge search for new methods of formation and optimization of the catalyst layers in order to reduce consumption of these metals.

The objectives of this paper are the studies of the possibilities of using ion beam technique for preparation of the electrocatalysts for the direct alcohol oxidation fuel cells, as well as of the composition and properties of the catalytic layers formed by ion beam assisted deposition of platinum and cerium from pulsed plasma arc onto carbon paper supports.

Cerium added to platinum is widely used in research as metal which activates a multi-step process of electrochemical oxidation of alcohol [5-9]. 
There were carried out the studies [10-14] of ionbeam formed catalytic layers on both metal and carbon substrates with smooth surfaces which indicated that upon the deposition of platinum from the pulsed vacuum plasma arc there are formed multicomponent amorphous surface layers of the thickness less than $100 \mathrm{~nm}$ having sufficiently high activity in the process of electrochemical oxidation of methanol and ethanol.

\section{Experimental details and results}

As electrocatalyst supports we selected special carbon materials: AVCarb ${ }^{\circledR}$ Carbon Fiber Paper (AVCarb CFP) (Ballard Material Products Inc.) and Toray Carbon Fiber Paper TGP-H-060 T (Toray CFP), which are destined for the production of diffusion layers of the membrane-electrode assemblies for low temperature fuel cells with a polymer electrolyte membrane.

The basis of the AVCarb CFP and Toray CFP carbon supports are polyacrylonitrile fibers which are subjected to thermal oxidative stabilization and subsequent carbonization; their basic characteristics are given in $[15,16]$. The nominal thickness of AVCarb CFP is $175 \mu \mathrm{m}$ and of Toray CFP $-190 \mu \mathrm{m}$. The support Toray CFP can be treated with polytetrafluoroethylene and its surface is hydrophobic; the support AVCarb CFP is not hydrophobic. Pretreatment of the surface of the carbon paper supports sample was not required.

Catalytic layers were prepared by the ion beam assisted deposition (IBAD) of platinum, as well as cerium and platinum onto the AVCarb CFP and Toray CFP carbon electrocatalyst supports. The deposition method is characterized by the use of deposited metal ions as assisting ones. Metal deposition and mixing between the precipitable layer and the substrate by the accelerated ions of the same metal were carried out from a neutral vapour fraction and the vacuum-arc discharge plasma of a pulsed electric arc ion source. The ion accelerating voltage is $10 \mathrm{kV}$; vacuum level is $10^{-2} \mathrm{~Pa}$.

The morphology and elemental composition of the obtained layers were studied by scanning electron microscopy (SEM) together with the electron probe energy dispersive X-ray microanalysis (EDX), wave dispersive $\mathrm{X}$-ray fluorescence analysis (WD-XRF), and the Rutherford backscattering spectrometry (RBS).

Electron microscopic study of the surface layers in conjunction with electron energy dispersive microanalysis was carried out using the complex scanning electron microscope and spectrometer: JSM-5610LV + EDX JED2201 (JEOL), and LEO 1455 VP + AZtec Energy Advanced X-Max80 (Oxford Instruments). Also the distribution of elements on the layer surfaces was analyzed. The energy of the electron beam scanning the surface of the materials was $20 \mathrm{keV}$.

The X-ray fluorescence analysis of the catalytic layers with the wavelength dispersion was made using the PANalytical Axios spectrometer. In order to excite the X-ray fluorescence of atoms embedded in the tested samples we have used Rh $K$-radiation; as a monochromator-analyzer — crystal LiF (200).
The study of the layers by the Rutherford backscattering spectrometry was carried out using the AN-2500 accelerator complex (High Voltage Engineering Europe). The spectra of the scattered ${ }^{4} \mathrm{He}$ ions at their initial energy $E_{0}=1.3 \mathrm{MeV}$ were taken at the normal incidence beam analyzing the particles on the surface of the sample and the scattering angle $\theta=170^{\circ}$. The energy resolution of the spectrometer with a surface-barrier silicon detector was $18 \mathrm{keV}$. Standard processing of the RBS spectra was performed.

Activity of electrocatalysts formed on the basis of carbon supports was studied in the electrochemical oxidation reactions of methanol and ethanol, the underlying principle of action of low temperature fuel cells. The research was carried out by cyclic voltammetry [17] using a standard three-electrode electrochemical cell, a potentiostat PI 50-1, programmer PR-8, an analog-to-digital converter and a PC (samples AVCarb CFP) and a potentiostat Autolab 302N (Toray CFP samples). The test sample was used as a working electrode, the platinum wire as an auxiliary electrode, and the saturated silver chloride half cell $(\mathrm{Ag} / \mathrm{AgCl})$ as a reference electrode. Potential values $U$ of the working electrode were calculated from the reference electrode potential. Measurements were carried out at $20^{\circ} \mathrm{C}$ in a solution of methanol and ethanol in sulfuric acid $\left(1 \mathrm{M} \mathrm{CH}_{3} \mathrm{OH}+0.5 \mathrm{M} \mathrm{H}_{2} \mathrm{SO}_{4}\right.$ and $\left.1 \mathrm{M} \mathrm{C}_{2} \mathrm{H}_{5} \mathrm{OH}+0.5 \mathrm{M} \mathrm{H}_{2} \mathrm{SO}_{4}\right)$. The prepared solutions based on distilled water from sulfuric acid marked "analytical grade", methanol Merck HPLC and rectified ethanol. The potential sweep speed of measurements in the potentiodynamic mode was 50 or $100 \mathrm{mV} / \mathrm{s}$.

The electron microscopic studies show that morphology of the carbon support surface during formation of catalyst layers on them does not change (Fig. 1). At the same time on the studied surface metal inclusions of several micrometers size are precipitated (Figs. 1-3) due to the deposition of metal droplets from the arc-discharge ion source.

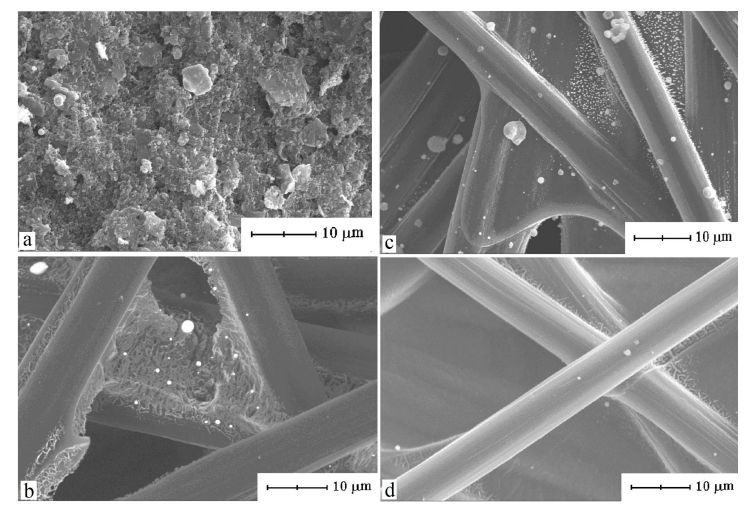

Fig. 1. SEM images of the catalytic layers prepared by platinum IBAD onto AVCarb ${ }^{\circledR}$ CFP (a) and Toray CFP TGP-H-060 T (b) catalyst supports, and cerium and platinum IBAD onto Toray CFP TGP-H-060 T (c) catalyst support, and initial sample (d) of Toray CFP TGP-H-060 T catalyst support. 

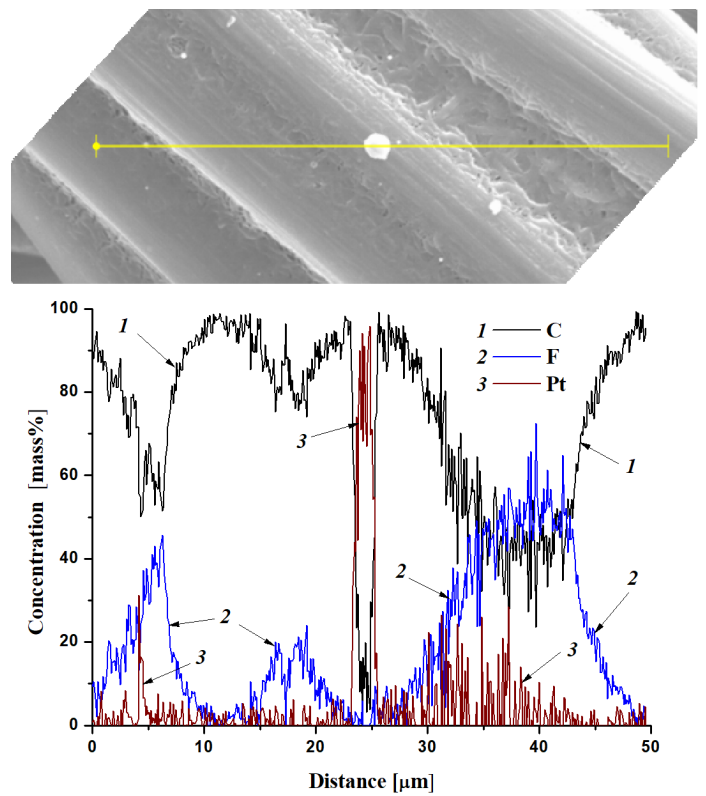

Fig. 2. Distribution of the elements along the scanning line in the catalytic layer prepared by platinum IBAD onto Toray CFP TGP-H-060 T catalyst support (according to EDX data).
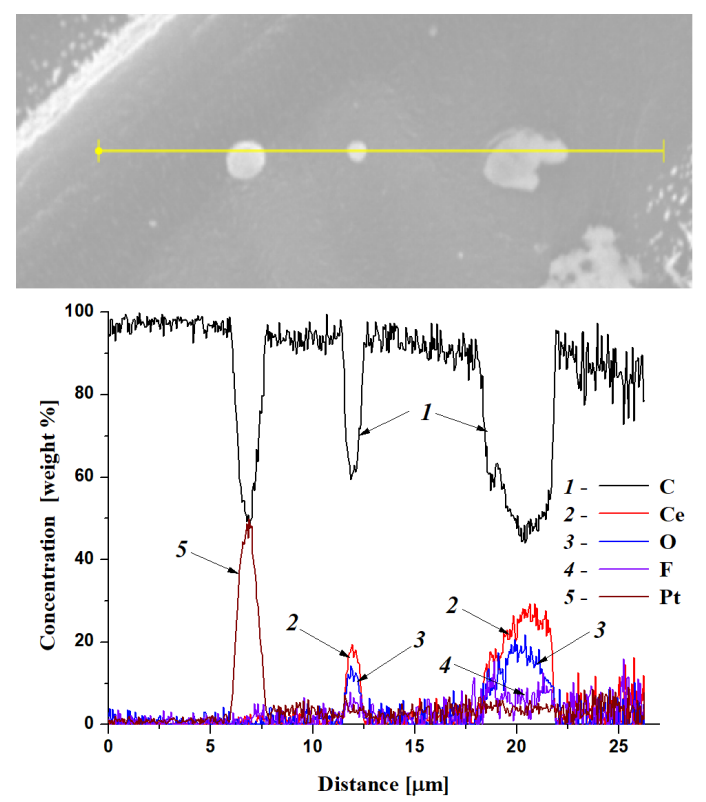

Fig. 3. Distribution of the elements along the scanning line in the catalytic layer prepared by cerium and platinum IBAD onto Toray CFP TGP-H-060 T support (according to EDX data).

Composition of catalytic layers under investigation includes (Figs. 2 and 3, Table I) atoms of deposited metals, carbon supports and oxygen impurities. The content of deposited platinum and cerium in the catalytic layers is several weight percent according to the electron dispersive microanalysis. The element concentrations in Table I obtained from the EDX measurement were calculated from the sample area $1.5 \times 1.0 \mathrm{~mm}$. Unlike AVCarb
TABLE I

Elemental composition of catalytic layers prepared by cerium and platinum IBAD onto AVCarb ${ }^{\circledR}$ CFP and Toray CFP TGP-H-060 T catalyst supports (EDX data).

\begin{tabular}{c|c|c|c}
\hline \multirow{2}{*}{ Element } & \multicolumn{3}{|c}{ Composition [wt\%] } \\
\cline { 2 - 4 } & $\mathrm{Pt} /$ AVCarb & $\mathrm{Pt} /$ Toray & $\mathrm{Ce}, \mathrm{Pt} /$ Toray \\
\hline $\mathrm{C}$ & 91.2 & 75.9 & 80.2 \\
\hline $\mathrm{F}$ & - & 11.2 & 2.7 \\
\hline $\mathrm{Pt}$ & 5.6 & 12.9 & 5.1 \\
\hline $\mathrm{Ce}$ & - & - & 6.1 \\
\hline $\mathrm{O}$ & 3.2 & - & 5.9
\end{tabular}

CFP the polytetrafluoroethylene treated Toray CFP catalyst support contains a significant amount of fluorine. The presence of oxygen results from deposition of residual atmosphere of working vacuum chamber and sorption processes. A significant amount of oxygen was found after a deposition of cerium (Table I) and in the precipitates of cerium (Fig. 3). Cerium oxides are assumed to be formed.

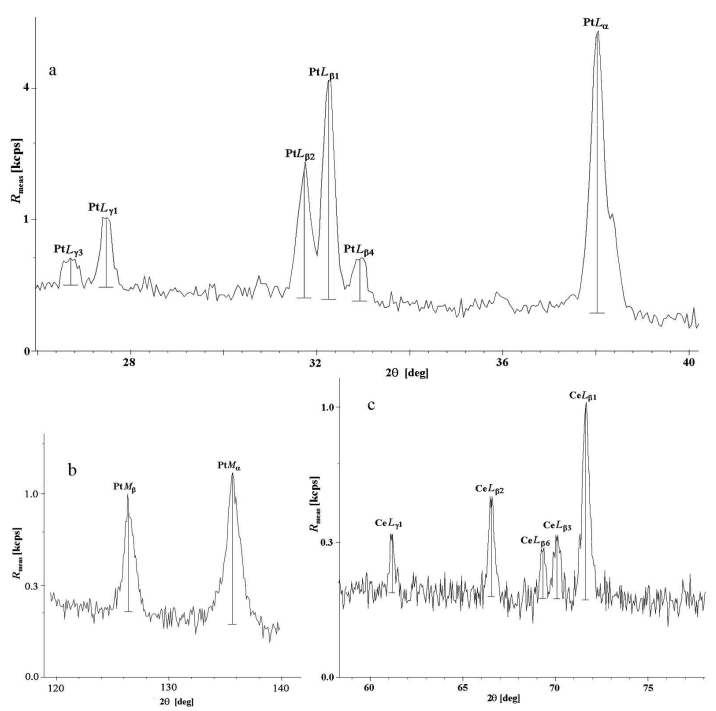

Fig. 4. Parts of the WD-XRF spectrum of the electrocatalyst prepared by cerium and platinum IBAD onto Toray CFP TGP-H-060 T catalyst support.

Study of the electrocatalysts using WD-XRF confirms their elemental composition. Figure 4 shows the X-ray fluorescence spectra parts of platinum and cerium atoms introduced into the catalytic layers prepared by IBAD on the Toray CFP catalyst support. The $L$ - and $M$ series spectral lines of characteristic X-rays of platinum atoms and $L$-series radiation of cerium atoms are observed. There is also a line of the $K_{\alpha}$-radiation from fluorine atoms (spectrum in Fig. 4 is not shown). The lines of the reflected radiation of rhodium atoms used as the exciting X-ray fluorescence are observed.

The data of Rutherford backscattering spectrometry of the electrocatalysts are shown in Fig. 5. The correct quantitative processing of the RBS spectra is difficult 


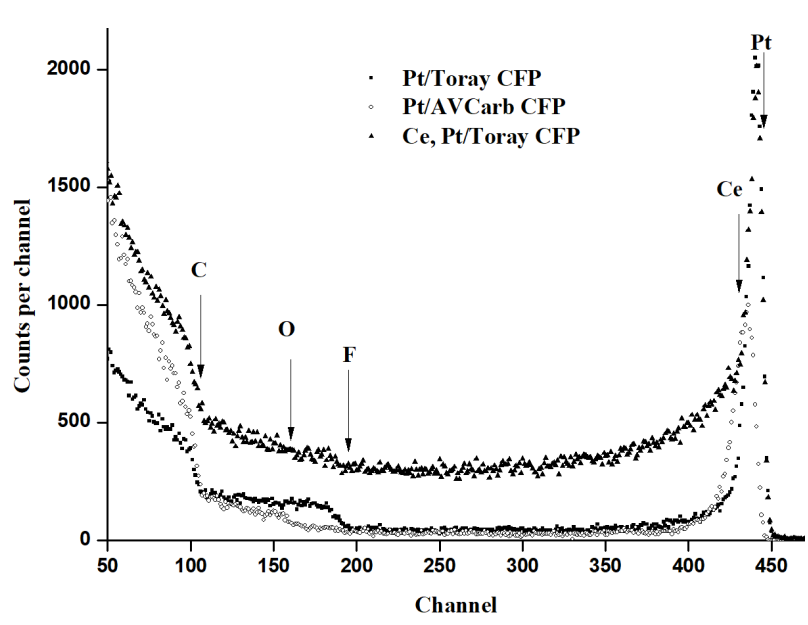

Fig. 5. RBS spectra of ${ }^{4} \mathrm{He}$ ions scattered from the electrocatalysts prepared by platinum and cerium IBAD onto carbon AVCarb ${ }^{\circledR}$ CFP and Toray CFP TGP-H$060 \mathrm{~T}$ catalyst supports.

because of irregular and porous structure of the AVCarb CFP and Toray CFP carbon supports. On the Ce spectrum of the Pt/Toray CFP sample (Fig. 5) there is a section indicating the cerium layer of significant thickness. This can prove remarkable contribution of spray cerium to the deposition process of layer compared to platinum IBAD.

The results of the study on the activity of electrocatalysts in the reactions of methanol and ethanol oxidation are shown in Figs. 6-8 in the form of cyclic voltammograms. Electrochemical oxidation of alcohols in the sulfuric acid solution at the cyclic voltammograms is shown as a specific current peak when changing the electrode potential in the anode and cathode areas [18]. On the anode side voltammograms a current peak is caused by a multistep process of oxidation of methanol or ethanol, which includes an electrochemical adsorption, decomposition of alcohol molecules and the formation of carbon monoxide adsorbed molecules $\mathrm{CO}_{a d s}$ and their subsequent removal by reaction with chemisorbed water molecules or with $\mathrm{OH}_{a d s}$ groups to form hydrogen ions and $\mathrm{CO}_{2}$. Reduction of current with a further increase in the potential of the electrode is observed due to the decrease rate of the process of electrochemical adsorption of alcohol molecules as a result of blocking the platinum on the electrocatalyst surface. On the subsequent sweep of potential in the cathode direction of the voltammogram current peak appears which is due to the resumption of the process of methanol or ethanol oxidation to the recovered catalyst surface [19-21].

These peaks clearly appear at the cyclic voltammogram of the electrocatalysts for all the samples (Figs. 6-8), indicating their activity in such reactions as oxidation of methanol and ethanol. Moreover, the activity of the electrocatalysts in oxidation of ethanol (1 M

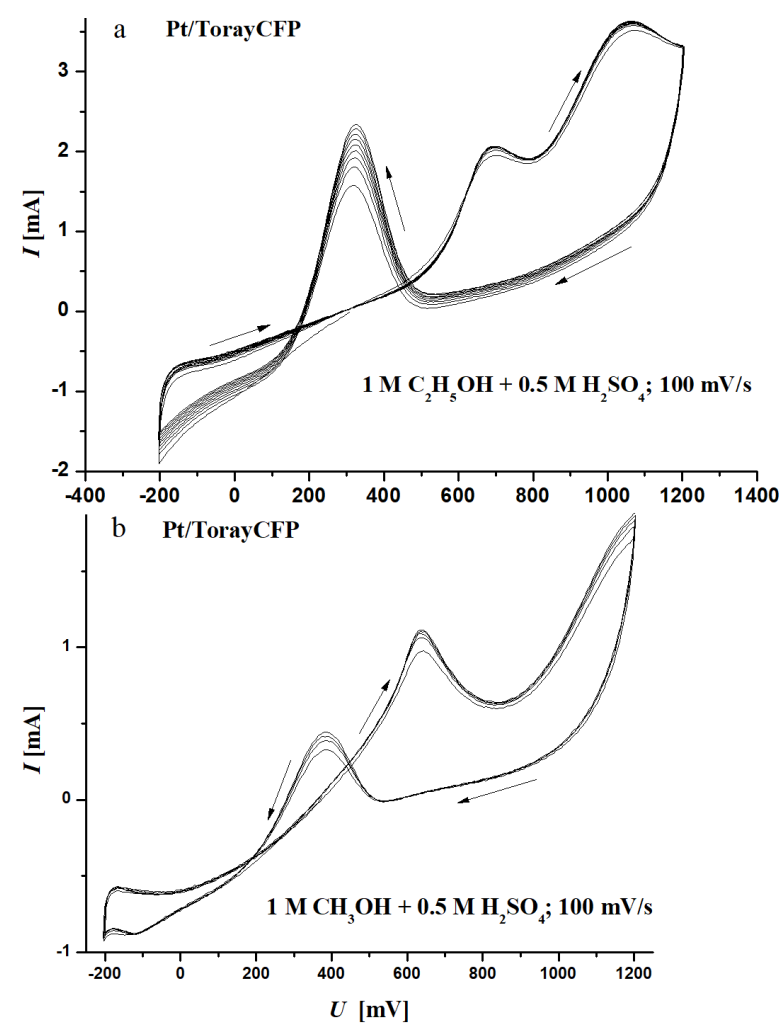

Fig. 6. Cyclic voltammograms of the electrocatalyst prepared by platinum IBAD onto Toray CFP TGP-H$060 \mathrm{~T}$ catalyst support obtained in ethanol comprising $1 \mathrm{M} \mathrm{C}_{2} \mathrm{H}_{5} \mathrm{OH}+0.5 \mathrm{M} \mathrm{H}_{2} \mathrm{SO}_{4}$ (a) and methanol (1 M $\mathrm{CH}_{3} \mathrm{OH}+0.5 \mathrm{M} \mathrm{H}_{2} \mathrm{SO}_{4}$ ) (b) solutions.

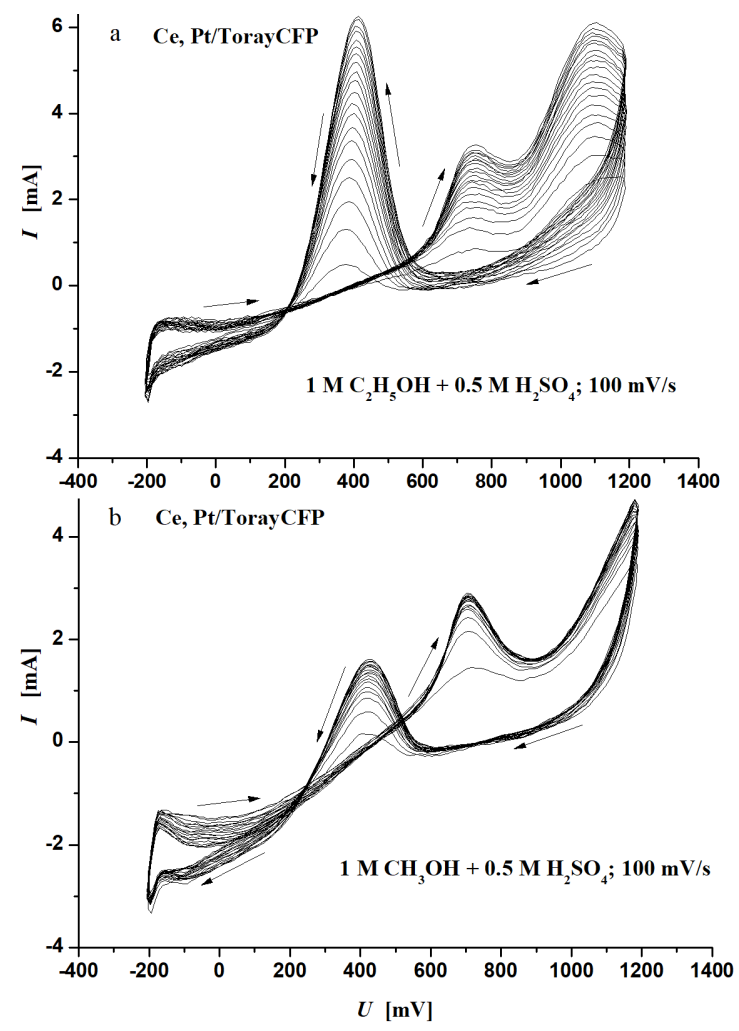

Fig. 7. As Fig. 6 for the electrocatalyst prepared by cerium and platinum IBAD. 


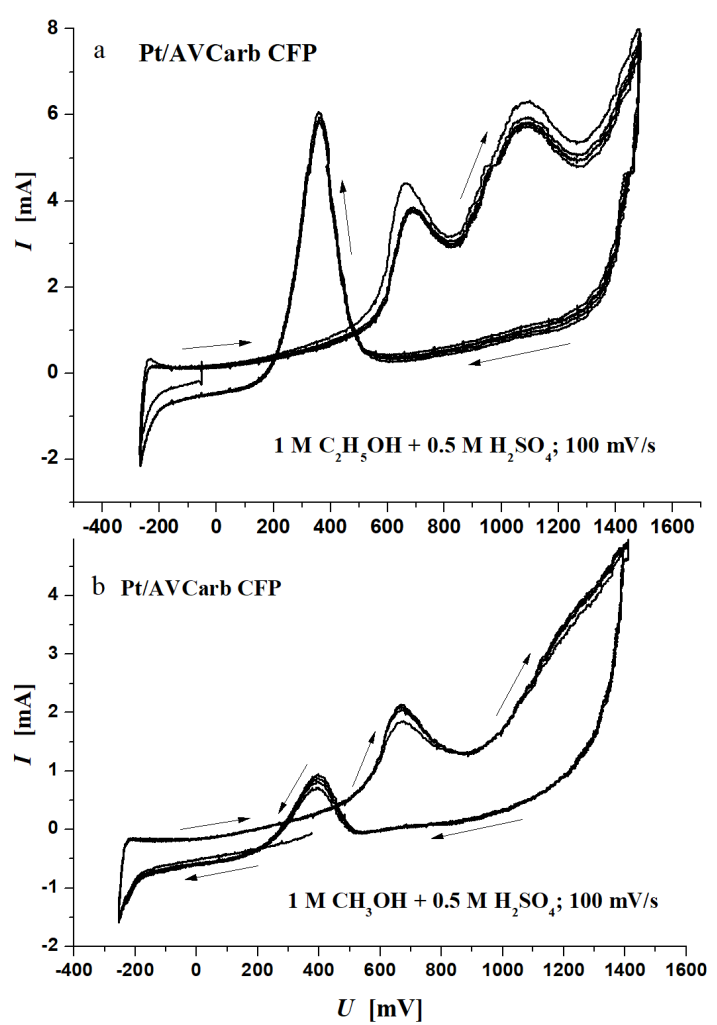

Fig. 8. As Fig. 6 for AVCarb ${ }^{\circledR}$ CFP P50.

$\mathrm{C}_{2} \mathrm{H}_{5} \mathrm{OH}+0.5 \mathrm{M} \mathrm{H}_{2} \mathrm{SO}_{4}$ solution, Figs. 6-8,a) is higher than in the oxidation reaction of methanol $(1 \mathrm{M}$ $\mathrm{CH}_{3} \mathrm{OH}+0.5 \mathrm{M} \mathrm{H}_{2} \mathrm{SO}_{4}$ solution, Figs. 6-8,b). The electrocatalysts containing cerium exhibit higher activity in oxidation reactions such as ethanol and methanol (compare Figs. 6 and 7).

\section{Conclusions}

Preparation of active layers on the carbon catalyst supports Toray CFP TGP-H-060 T and AVCarb ${ }^{\circledR}$ CFP P50 were conducted by the ion beam assisted deposition of cerium and platinum from a neutral vapour fraction and the vacuum arc discharge plasma of a pulsed electric arc ion source, respectively. These special carbon materials are destined for the production of diffusion layers of the membrane-electrode assemblies of low temperature fuel cells with a polymer electrolyte membrane, in particular DMFC and DEFC.

According to scanning electron microscopy, the morphology of the carbon support surface in forming the catalytic layers on them does not change. With the use of electron probe energy dispersive microanalysis, the wave dispersive X-ray fluorescence analysis and Rutherford backscattering spectrometry revealed that the composition of the catalytic layers contains atoms of deposited metals and elements included in the support. The content of each deposited metal is several percent by weight.

Electrocatalysts with the surface layers formed on the carbon fiber catalyst supports by the ion beam assisted deposition in the proposed mode exhibit activity in important and practical attitude oxidation processes of methanol and ethanol organic alcohols. They differ in the very low (less than $0.05 \mathrm{mg} / \mathrm{cm}^{2}[10-14]$ ) platinum content, whereas the platinum content in the electrocatalysts for DMFC and DEFC, which are used at present, is $1-5 \mathrm{mg} / \mathrm{cm}^{2}$. Formation of an active surface during the ion beam assisted deposition of the two metals is carried out under vacuum conditions in two steps which compares favorably with the conventional multistage chemical methods for the preparation of supported catalysts based on impregnation of the support with the solutions of compounds of each metal, their reduction to the metallic state, drying and etc.

\section{References}

[1] G.K. Wolf, R. Spiegel, K. Zucholl, Nucl. Instrum. Methods Phys. Res. B 19/20, 1030 (1987).

[2] V.V. Poplavskij, Nucl. Instr. Methods Phys. Res. B 28, 534 (1987).

[3] G.K. Wolf, Nucl. Instrum. Methods Phys. Res. B 46 369 (1990).

[4] F.F. Komarov, V.V. Poplavskij, Radiat. Eff. 106, 1 (1988).

[5] W. Hariyanto, W. Purwanto, W.-S. Roekmijati, U. Stimming, J. Chem. Natural Resources Engineering, FKKKSA, Universiti Teknologi Malaysia 2, 47 (2007).

[6] A.M. Sheikh, Kh. Ebn-Alwaled Abd-Alftah, C.F. Malfatti, J. Multidisciplin. Eng. Sci. Technol. 1, 1 (2014).

[7] Ye Wang, Shouzhong Zou, Wen-Bin Cai, Catalysts 142, 1507 (2015).

[8] Changwei Xu, Pei Kang Shen, J. Power Sources 142, 27 (2005).

[9] Han Xu, An-Liang Wang, Ye-Xiang Tong, Gao-Ren Li, ACS Catal. 6, 5198 (2016).

[10] V.V. Poplavskii, T.S. Mishchenko, V.G. Matys, J. Surf. Invest. 4, 576 (2010).

[11] V.V. Poplavskii, T.S. Mishchenko, V.G. Matys, Tech. Phys. 55, 296 (2010).

[12] V.V. Poplavskii, T.S. Stel'makh, V.G. Matys, J. Surf. Invest. 6, 748 (2012).

[13] V.V. Poplavskii, A.V. Dorozhko, J. Surf. Invest. 7, 303 (2013).

[14] V.V. Poplavsky, A.V. Dorozhko, V.G. Matys, Izv. Vuzov. Phizica (Rus.) 57, 216 (2014).

[15] AvCarb Datasheets, (accessed: 18.05.2016).

[16] Toray Carbon Fiber Paper TGP/H (accessed: 18.05.2016).

[17] E.J. Rudd, Thin Solid Films 43, 1 (1977).

[18] W. Vielstich, Brennstoffelemente, Verlag Chemie, Weinheim 1965.

[19] W. Vielstich, J. Bras. Soc. 14, 503 (2003).

[20] T. Iwasita, Electrochim. Acta 47, 3663 (2002).

[21] S. Sriramulu, T.D. Jarvi, E.M. Stuve, J. Electroanal. Chem. 467, 132 (1999). 